\title{
Akut Tüm Vücut Vibrasyon Antrenmanının Ünilateral Statik Dengeye Etkilerinin İncelenmesi
}

\author{
Celil KAÇOĞLU ${ }^{1 *}$ (D) \\ ${ }^{1}$ Eskişehir Teknik Üniversitesi, Spor Bilimleri Fakültesi, ESKIŞEHIR
}

DOI: 10.31680/gaunjss.528141

Orijinal Makale / Original Article

Geliş Tarihi / Received: 17.02.2019 Kabul Tarihi / Accepted: 19.03.2019 Yayın Tarihi / Published: 22.03.2019

\section{Öz}

$\mathrm{Bu}$ araştırmanın amacı tüm beden vibrasyon (TBV) antrenman uygulamasının ünilateral statik dengeye etkilerinin incelenmesidir. Bu çalışmaya 18-22 yaş arası fiziksel olarak aktif ve sağlıklı (kadın:16, erkek:14) 30 birey (yaş: $21.9 \pm 2.4$ yıl, boy: $173.7 \pm 7.1 \mathrm{~cm}$, vücut ağırlığı: $70.0 \pm 11.6 \mathrm{~kg}$ ) gönüllü olarak katılmıştır. Katılımcılar rastgele eşit olarak iki gruba ayrılmıştır. TBV antrenmanı bir vibrasyon platformunda $120^{\circ} \mathrm{diz}$ eklem açısında statik squat hareketi sırasında $30 \mathrm{~Hz}$ frekansta, $2 \mathrm{~mm}$ genlikle $2 \times 60 \mathrm{sn}$ şeklinde uygulanmıştır. Her iki grup aynı vibrasyon antrenmanını uygulamışlardır. Bir gruba vibrasyon antrenmanı sonrası 3dk diğer gruba ise $5 \mathrm{dk}$ pasif dinlenme verilmiştir. Vibrasyon öncesi ve sonrası yapılan denge ölçümleri (Sportkat $4000^{\circledR}$ ) 30 sn süreli sağ ve sol ayak ünilateral statik denge ölçümlerini içermektedir. Faktöriyel ANOVA sonuçlarına göre vibrasyon sonrası 3 ve 5 dakika dinlenme verilen gruplar arasında tüm denge hata puanlarında istatistiksel olarak anlamlı fark olmadığı görülmüştür $(p>0.05)$. Grup içi farkın belirlenmesi için yapılan eşleştirilmiş örneklem T-testi sonuçlarına göre ise ön test ve son test denge hata puanları arasında farklılık olmadığı görülmüştür $(p>0.05)$. Bu bulgulara göre akut vibrasyon antrenmanının bu parametrelerle uygulanan $(2 \times 60 \mathrm{sn}, 30 \mathrm{~Hz}, 2 \mathrm{~mm})$ formunun sağlıklı bireylerde denge yeteneğini geliştirici adaptasyon sağlamadığı sonucuna ulaşılımıştır. İleride yapılacak çalışmalarda uzun dönem vibrasyon antrenman programlarının veya farklı vibrasyon parametrelerinden oluşan antrenman formlarının dengeye veya atletik performansa etkileri araştırılabilir.

Anahtar Kelimeler: Denge, Titreşim, Akut etki, Spor, Ön kondisyonlanma

\section{An Investigation of The Effects of Acute Whole Body Vibration Training on Unilateral Static Body Balance}

\begin{abstract}
The aim of this study is to investigate the effects of whole-body vibration (TBV) training on unilateral static body balance. Thirty physically active and healthy subjects (female: 16, male: 14) between the ages of 18-22 (age: 21.9 \pm 2.4 years, height: $173.7 \pm 7.1 \mathrm{~cm}$, body weight: $70.0 \pm 11.6 \mathrm{~kg}$ ) volunteered in this study. The participants were divided into two equal groups. The TBV training was performed at a frequency of $120^{\circ}$ knee bend on a vibration platform at a frequency of $30 \mathrm{~Hz}$ and $2 \mathrm{~mm}$ amplitude during static squat movement and $2 \times 60 \mathrm{sec}$. Both groups applied the same vibration training. One group was given $3 \mathrm{~min}$ and the other one $5 \mathrm{~min}$ passive rest after the vibration training. Body balance measurements made before and after vibration with 30 -second left and right leg unilateral static balance measurement. According to the results of the factorial ANOVA, there were no significant differences in all body balance error scores between the groups which were given 3 and 5 minutes passive rest after vibration $(p>0.05)$. According to the results of the paired sample T-test performed to determine the difference within the group, there was no difference between the pre-test and post-test balance error scores ( $p>$ $0.05)$. According to these findings, it is concluded that the acute vibration training $(2 \times 60 \mathrm{sec}, 30 \mathrm{~Hz}, 2 \mathrm{~mm})$ form which is applied with these parameters does not provide adaptation to develop the body balance ability of healthy individuals. In future studies, effects of long-term vibration training programs or training forms consisting of different vibration parameters on balance or athletic performance can be investigated.
\end{abstract}

Keywords: Balance, Vibration, Acute effect, Sport, Preconditioning

\footnotetext{
* Sorumlu Yazar:Celil KAÇOĞLU
}

E-mail: ckacoglu@eskisehir.edu.tr 
Kaçoğlu, C. (2019). Akut Tüm Vücut Vibrasyon Antrenmanının Ünilateral Statik Dengeye Etkilerinin İncelenmesi. Gaziantep Üniversitesi Spor Bilimleri Dergisi, 4(1), 144-156.

\section{Giriş}

Vibrasyon, bir titreşim platformunun ürettiği titreşim hareketinin bireyin genellikle ayaklarından başlayarak tüm vücuduna iletilmesi şeklinde tanımlanabilir (Sa-Caputo ve ark., 2014). Vücuda iletilen bu titreşimin sonucu oluşan mekanik uyarı tendonlara iletilir daha sonra da alfa motor nöronları aktive ederek kas kontraksiyonu oluşturur. Bu süreç "tonik vibrasyon refleksi (TVR)" olarak tanımlanmaktadır (Dallas ve ark., 2014).

Literatürde vibrasyon antrenmanlarının kas kuvvetine (Delecluse ve ark., 2003; Roelants ve ark., 2004), sıçramaya (Delecluse ve ark., 2003; Kim ve ark., 2016), esnekliğe (Cochrane ve Stannard, 2005; Fagnani ve ark., 2006; Sands ve ark., 2006), dengeye (Despina ve ark., 2014; Ritzmann ve ark., 2014; Dallas ve ark., 2014; Cloak ve ark., 2016), eklem hareket açısına (Cochrane, 2013), kemik kuvvetine (Cardinale and Rittweger 2006), vücut kompozisyonuna (Aykora ve ark., 2017; Demirel ve ark., 2017) olumlu etkileri olduğunu gösteren araştırmalar bulunmaktadır.

Vibrasyonun alt ekstremitelerde güç üretim kapasitesini arttırma potansiyeli ve nöromuskuler sistemlere etkileri olmasından dolayı egzersiz amaçlı kullanımı giderek yaygınlaşmaktadır (Cardinale ve Wakeling, 2005).Vibrasyonun, antrenman yöntemi olarak popülerliğinin artmasına rağmen insanlarda vibrasyona yanıt mekanizması net olarak anlaşılmış değildir (de Paula ve ark., 2017). Buna rağmen titreşimin nöromuskuler performansa etki mekanizmalarının; refleks kas aktivasyonları oluşturma etkisinden, plyometrik antrenman benzeri yer çekimini arttırma etkisinden, deri altı mekanoreseptörleri uyarma etkisinden ayrıca proprioseptif ve hormonal etkilerden kaynaklı olabileceği belirtilmiştir (Cardinale ve Bosco, 2003; Rittweger, 2010).

Vibrasyon egzersizlerinin etkileri büyük oranda frekans $(\mathrm{Hz})$, genlik $(\mathrm{mm})$, uygulama süresi ( $\mathrm{dk}$ ya da sn) ve vibrasyon sırasında ortaya çıkan ivmenin verdiği güç $\left(\mathrm{ms}^{-2}\right.$ ya da $\left.\mathrm{g}\right)$ değişkenlerinden etkilenmektedir. Frekans, titreşim döngülerinin saniyedeki tekrar sayısı, genlik titreşim platformunun aşağı ve yukarı yönlü hareket mesafesi olarak tanımlanmaktadır (Cardinale ve Bosco, 2003; Cochrane, 2013; Türkmen ve Nezire, 2016).

Tüm beden vibrasyonunun (TBV) sıçrama performansına olumlu etkileri olduğunu gösteren çalışmaların (Kırkaya ve ark., 2015; Kim ve ark., 2016) yanında etkisinin olmadığını (Kaçoğlu ve Gürol, 2016) hatta negatif etkisinin olduğunu (Rittweger ve ark., 2000) belirten araştırma sonuçları bulunmaktadır. Bu araştırma 
Kaçoğlu, C. (2019). Akut Tüm Vücut Vibrasyon Antrenmanının Ünilateral Statik Dengeye Etkilerinin İncelenmesi. Gaziantep Üniversitesi Spor Bilimleri Dergisi, 4(1), 144-156.

örneklerinin sonuçlarındaki çeşitliliğin vibrasyon antrenman metotlarındaki farklılıklardan kaynaklandığını söylemek yanlış olmayacaktır. Akut vibrasyon uygulamasının post aktivasyon potansiyeli (PAP) ortaya çıkardığı bilinmektedir (Cochrane ve ark., 2010). PAP, sporcularda genel ve özel ısınmayı takiben yapılan maksimal ya da maksimale yakın şiddetteki ön kondisyonlanma aktivitesi sonrası, yüksek hız veya şiddette pliometrik formdaki bir aktivitenin performansında ortaya çıkan akut artış olarak tanımlanabilir (Kaçoğlu ve Yıldırım, 2017). Ön kondisyonlanma aktivitesi olarak vibrasyonun kuvvet (Cochrane ve ark., 2010) ve sprint (Ronnnestad ve Ellefsen, 2011) performanslarına akut etkileri olduğunu ortaya koyan birçok çalışma bulunmaktadır. Vibrasyonun tendon refleksi (Cochrane ve ark., 2010), Hrefleksi (Armstrong ve ark., 2008), I-a afferent sinirlerde uyarılma (Dolny ve Reyes, 2008), motor nöron uyarılabilirliği (Mcbride ve ark., 2010), eklem hareket açı algısı (Fontana ve ark., 2005), ayak bileği stabilizasyonu (Melnyk ve ark., 2009), kas iğcikleri ve duyu reseptörleri (Delecluse ve ark., 2003) gibi denge performansında önemli olan nöromuskuler etkileri, vibrasyonun ön kondisyonlanma aktivitesi olarak uygulandığında denge performansına etkileri olup olmadığını düşündürmektedir (Aydog ve ark., 2005).

Vibrasyon egzersizlerinin denge üzerine pozitif etkileri olduğunu ortaya koyan çalışmaların (Torvinen ve ark., 2002a; Bogaerts ve ark., 2007; Kawanabe ve ark., 2007; Despina ve ark., 2014; Ritzmann ve ark., 2014; Cloack ve ark., 2016) yanı sıra dengeye etkisinin bulunmadığını gösteren çalışmalar da bulunmaktadır (Torvinen ve ark., 2002b). Literatürde yapılan incelemelerde TBV antrenmanlarının dengeye etkileri konusunda yapılmış çalışmaların çoğunluğunun yaşlı bireylerde rehabilitasyon amaçlı olduğu ve bu popülasyonda TBV antrenmanlarının dengeyi geliştirdiği belirtildiği görülmüştür (Bautmans ve ark., 2005; Cheung ve ark., 2007). Fiziksel olarak aktif bireylerde TBV antrenmanlarının atletik performansa etkileriyle ilgili daha fazla ulusal çalışmalara intiyaç vardır. Sağlıklı bireylerde vibrasyonun ünilateral dengeye akut etkilerini inceleyen ulusal araştırma sonuçlarına ulaşılamamış olmasından dolayı bu araştırmanın amacı tek bir TBV antrenmanının ünilateral statik dengeye akut etkilerini incelemektir.

\section{Yöntem}

Bu çalışmaya fiziksel olarak aktif, haftada en az 2 gün düzenli fiziksel aktivitelere katılan sağlıklı 18-22 yaş arası kadın (n:16) ve erkek (n:14) 30 birey (yaş: 
Kaçoğlu, C. (2019). Akut Tüm Vücut Vibrasyon Antrenmanının Ünilateral Statik Dengeye Etkilerinin İncelenmesi. Gaziantep Üniversitesi Spor Bilimleri Dergisi, 4(1), 144-156.

21.9 \pm 2.4 yıl, boy: $173.7 \pm 7.1 \mathrm{~cm}$, vücut ağırlığı: $70.0 \pm 11.6 \mathrm{~kg}$ ) gönüllü olarak katılmıştır.

TBV antrenmanları her ne kadar performans geliştirme amacıyla kullanılsa da, titreşimin insan üzerinde olumsuz etkileri olduğu da rapor edilmiştir (Jordan ve ark., 2005; Fratini ve ark., 2009). Bu olumsuz etkiler arasında algısal illüzyonlar, bazı reflekslerde değişme, 4-5 Hz aralığında frekanslarda sindirim sistemine etki, kas yorgunluğu, huzursuzluk, konuşma bozukluğu 2-20 Hz aralığında kardiovasküler sistemde orta seviyeli egzersiz etkisi $120 \mathrm{~Hz}$ ve üstündeki frekanslarda ise ölümcül kalp atımlarına yol açabildiği belirtilmiştir (Poston ve ark., 2007; Jordan ve ark., 2005). Bunun yanına titreşimin kısa süreli etkileri arasında, kalp atımında artış, hiperventilasyon, baş ağrısı, yol tutması uzun süreli etkileri arasında ise, omurgada özellikle toraks ve lumbar omurlarda dejenerasyon, omurga disk rahatsızlığı, bel ağıısı ve gastrointestinal bozulmalar, kas ve sinir dokusu hasarı, Raynaud fenomeni bulunmaktadır (Smith ve Leggat, 2005; Fratini ve ark., 2009). Bu tür yan etkilerin rapor edildiği çalışmalardaki katıımcıların daha çok sedanterler ve ileri yaş grupları olduğu göz önünde bulundurulmalıdır. Düzenli olarak egzersiz yapan aktif bireylerde ise mevcut kas koordinasyonuna bağı olarak birçok parametre için olumlu sonuçlar elde edilmiştir. Bu nedenle de bu çalışmada belirtilen yan etkilerle ilgili herhangi bir risk öngörülmemiş olup tüm katılımcılar çalışma öncesinde sağlık kontrolünden geçirilmişlerdir.

Katıımcılar rastgele olacak şekilde vibrasyon sonrası 3 dakikalık (grup3) ve 5 dakikalık (grup5) pasif dinlenme gruplarına ayrılmıştır. Tüm katıımcılar deneme ve alıştırma seansında test ve vibrasyon antrenmanına birebir olacak şekilde katılmışlardır. Deneme ve tanıtım ölçümlerinden yaklaşık 10 gün sonra ise asıl testlere katılmışlardır. Ölçümler için Eskişehir Teknik Üniversitesi Spor bilimleri Fakültesi Laboratuvarlarından yararlanılmıştır. Katılımcıların ilk test günü öncesi öncelikle boy, kilo, vücut yağ yüzdesi ile ilgili bilgileri alınmıştır. Tüm test ve antrenmanlardan önce yaklaşık 10 dakikalık submaksimal esnetme, germe ve dinamik kontraksiyonlar içeren (konsantrik, pliometrik kalistenikler ve çeşitli sıçramalar gibi) standart ısınmalar uygulanmıştır. Isınma sonrası pasif dinlenme amaçı 2-3 dakika ara verildikten sonra ön test denge ölçümleri yapılmıştır. Sonrasında vibrasyon platformunda (Powerplate Pro 5 Airdaptive ${ }^{\circledR}$, Northbrook, ABD) diz eklem açısı mobil uygulamayla (İphone $8^{\circledR}$, iOS 12.1.4, Apple Inc., ABD) kontrol edilerek $120^{\circ}$ olacak şekilde ayakkabısız şekilde 1 dakika statik squat pozisyonunda 
Kaçoğlu, C. (2019). Akut Tüm Vücut Vibrasyon Antrenmanının Ünilateral Statik Dengeye Etkilerinin İncelenmesi. Gaziantep Üniversitesi Spor Bilimleri Dergisi, 4(1), 144-156.

durmuşlardır (Bosco ve ark., 2000; Kim ve ark., 2016; Ullucci ve ark., 2019). Bu uygulama 2 set şeklinde uygulanmış setler arası 1 dakikalık pasif dinlenme verilmiştir. Titreşim frekansı $30 \mathrm{~Hz}$, amplitüdü ise $2 \mathrm{~mm}$ olarak belirlenmiştir (Dallas ve ark., 2014). Katılımcıların statik denge ölçümleri 30 saniye süreli sağ ve sol tek ayak olarak laboratuvar ortamında kinestetik denge cihazı ile değerlendirilmiştir (SPORTKAT $4000^{\circledR}$, Berg Inc., ABD). Test esnasında eller omuzlarda çapraz, boştaki bacak ise diz $90^{\circ}$ ve diğer bacağa değmeyecek şekilde, gözler ise yaklaşık 1 metre mesafedeki ekrandaki imlece odaklıdır. Bu testte katıımcı ekrandaki imleci mümkün olduğunca merkez noktada sabit tutmaya çalışmaktadır. Merkezden sapmalar hata puanı olarak cihaz tarafından kaydedilmektedir. Dolayısıyla test sonucu elde edilen puan ne kadar düşük ise denge yeteneği o kadar gelişmiş olarak yorumlanmaktadır. Her ölçüm öncesi katılımcılara test yöntemi ve ölçümler hakkında tekrar bilgi verilmiştir. Bu şekilde TBV sonrası 3 dakika ve TBV sonrası 5 dakika olmak üzere birer hafta arayla iki kez ölçüme katılmışlardır. Araştırma için Eskişehir Osmangazi Üniversitesi Girişimsel Olmayan Etik Kurulu'ndan etik onay alınmıştır (Tarih: 11.12.2018, Sayı: 25403353-050.99-E.134848, Karar no: 5). Araştırmanın tamamının etik standartlara ve Helsinki Deklarasyonuna uygun şekilde yürütülmesine özen gösterilmiştir.

\section{Verilerin Analizi}

Bütün veriler ortalama ve standart sapma olarak verilmiştir. Normal Q-Q Plot Grafiklerine ve Shapiro-Wilks analizine verilerin normal dağıldığı ve kutu grafikleriyle uç değer olmadığı görülmüştür. Her iki grubun ön test ve son test denge ölçümleri arası fark olup olmadığını belirlemek için karışık ölçümlerde faktöriyel (2x2) varyans analizinden yararlanılıştır. Varyans ve kovaryansların eşitliğinin belirlenmesi için Mauchly küresellik testi kullanılış, bu varsayım sağlanmadığında ise GreenhouseGeisser düzeltmesi kullanılmıştır. Gruplar içi ön test son test arası farkın tespiti için eşleştirilmiş örneklem T-testi kullanılmıştır. İstatistiksel anlamlılık düzeyi $p<0.05$ olarak belirlenmiştir. Tüm istatistiksel hesaplamalar için SPSS v.20 yazılımı kullanılmıştır.

\section{Bulgular}

Her iki grubun ön ve son test ortalama denge hata puanları Tablo 1'de belirtilmiştir. 
Kaçoğlu, C. (2019). Akut Tüm Vücut Vibrasyon Antrenmanının Ünilateral Statik Dengeye Etkilerinin İncelenmesi. Gaziantep Üniversitesi Spor Bilimleri Dergisi, 4(1), 144-156.

Tablo 1. Grupların ön ve son test ortalama denge hata puanları

Denge hata puanları Sağ taraf ünilateral denge test sonuçları

\begin{tabular}{lcccccc}
\hline & \multicolumn{2}{c}{ Grup3 } & \multicolumn{4}{c}{ Grup5 } \\
\hline & Ön test & Son test & $p$ & Ön test & Son test & $p$ \\
\hline Genel & $414.9 \pm 67.5$ & $417.5 \pm 103.9$ & 0.926 & $374.1 \pm 90.5$ & $401.4 \pm 112.8$ & 0.135 \\
\hline Lateral (Sol) & $128.6 \pm 88.4$ & $156.8 \pm 85.1$ & 0.405 & $256.5 \pm 77.7$ & $220.3 \pm 108.9$ & 0.591 \\
\hline Medial (Sağ) & $286.4 \pm 126.2$ & $260.7 \pm 126.7$ & 0.583 & $169.3 \pm 66.4$ & $208.1 \pm 88.7$ & 0.107 \\
\hline Anterior (Ön) & $246.7 \pm 130.7$ & $273.9 \pm 180.5$ & 0.384 & $230.7 \pm 72.2$ & $325.7 \pm 170.1$ & 0.107 \\
\hline Posterior (Geri) & $168.0 \pm 124.6$ & $143.8 \pm 131.1$ & 0.326 & $110.1 \pm 64.9$ & $99.7 \pm 78.9$ & 0.504 \\
\hline \hline
\end{tabular}

Sol taraf ünilateral denge test sonuçları

\begin{tabular}{lcccccc}
\hline & \multicolumn{2}{c}{ Grup3 } & \multicolumn{3}{c}{ Grup5 } \\
\hline & Ön test & Son test & $p$ & Ön test & Son test & $p$ \\
\hline Genel & $371.9 \pm 73.9$ & $362.2 \pm 61.7$ & 0.726 & $350.2 \pm 56.8$ & $328.6 \pm 52.5$ & 0.107 \\
\hline Lateral (Sol) & $166.2 \pm 96.6$ & $190.8 \pm 91.5$ & 0.389 & $193.4 \pm 92.3$ & $183.4 \pm 83.8$ & 0.554 \\
\hline Medial (Sağ) & $205.9 \pm 106.5$ & $172.6 \pm 106.8$ & 0.391 & $174.7 \pm 76.2$ & $140.3 \pm 57.2$ & 0.507 \\
\hline Anterior (Ön) & $246.9 \pm 123.8$ & $218.9 \pm 118.8$ & 0.338 & $252.1 \pm 99.2$ & $243.9 \pm 73.1$ & 0.408 \\
\hline Posterior (Geri) & $125.1 \pm 96.1$ & $144.5 \pm 107.3$ & 0.474 & $77.3 \pm 38.9$ & $86.2 \pm 61.5$ & 0.694 \\
\hline
\end{tabular}

(Ortalama \pm Standart sapma)

Karışık ölçümlerde faktöriyel (2x2) varyans analizi sonuçlarına göre vibrasyon sonrası 3 ve 5 dakika dinlenme verilen gruplar arasında denge hata puanlarında anlamlı farklılık olmadığı görülmüştür $(p>0.05)$. Buna rağmen istatistiksel olmasa da Tablo 1'de görüldüğü gibi grup3'te ön test son test sonuçlarına göre sağ ayak denge sonuçlarında lateral ve posterior (sağ ve geri), sol ayak denge sonuçlarında medial ve posterior (sağ ve geri) yönlü denge kayıplarında azalma, yine grup3’te sol ayak denge değerlerinde posterior, medial ve anterior yönlü denge kayıplarında küçük oranda azalmalar olduğu görülmektedir. Grup5'te ise ön test ve son test değerlerine göre sağ ayak denge sonuçlarına göre posterior yönlü denge kayıplarda küçük oranda azalma sol ayak denge sonuçlarına göre ise lateral, medial ve anterior yönlü denge kayıplarında istatistiksel olmayan küçük azalmalar olduğu görülmektedir.

\section{Tartışma ve Sonuç}

$\mathrm{Bu}$ araştırmanın amacı vibrasyon antrenmanlarının statik denge üzerine etkilerinin incelenmesidir. Araştırmanın sonuçları $120^{\circ}$ statik squat pozisyonunda 1 
Kaçoğlu, C. (2019). Akut Tüm Vücut Vibrasyon Antrenmanının Ünilateral Statik Dengeye Etkilerinin İncelenmesi. Gaziantep Üniversitesi Spor Bilimleri Dergisi, 4(1), 144-156.

dakikalık 2 set uygulanan vibrasyon egzersizlerinin $(30 \mathrm{~Hz}, 2 \mathrm{~mm})$ sağlıklı genç bireylerde ünilateral statik denge üzerine etkisi olmadığını göstermiştir. Bunun yanında vibrasyon sonrası 3 ve 5 dakikalık pasif dinlenmenin dengede benzer sonuçlar ortaya koyduğu görülmüştür. Buna göre vibrasyonun denge performansına akut etkisi olmadığı söylenebilir.

Bu sonuçlar Torvinen ve ark., (2002a, 2002b) sağlıklı bireylerde 4 dakikalık vibrasyon uygulamasını izleyen 2 ve 60 dakika dinlenme sonrası denge performansında farklılık olmadığını belirttikleri çalışmalarının sonuçlarıyla benzerlik göstermektedir. Buna göre vibrasyon sonrası 3 ve 5 dakikalık dinlenme sonrası ölçülen dengenin 2 dakika ve 60 dakika sonrası ölçülen denge sonuçlarıyla benzer olduğu söylenebilir. Yine benzer olarak sağlıklı yetişkin bireylerde 4 aylık (haftada 3-5 kez, 4 dakika) ayakta duruş, squat, hafif sıçramalar ve değişmeli olarak tek ayak duruş hareketleri içeren vibrasyon antrenmanın (4x60sn, 4dk, 150Hz, 10mm) dengeye etkisi olmadığı belirtilmiştir (Torvinen ve ark., 2002c). Melnyk ve ark., (2009) sağlıklı bireylerde yaptıkları 4 haftalık, (haftada 3 gün, $3 \mathrm{dk}, 30 \mathrm{~Hz} 4 \mathrm{~mm}$ ) vibrasyon çalışmalarında inversiyon hareketi sırasındaki ayak bileği eklemi stabilizasyonunun değişmediğini belirtmişlerdir (Melnyk ve ark., 2009). Bu sonuçlara göre genç bireylerde vibrasyonun denge yeteneği üzerine etkisinin olmadığı söylenebilir. Sağlıklı bireylerde vibrasyon çalışmalarının yanında sporcularda yapılan benzer sonuçlara sahip vibrasyon çalışmaları da bulunmaktadır. Mahieu ve ark., (2006) çalışmalarında genç kayakçılarda (9-15 yaş) 6 hafta, haftada 3 gün dinamik squatlar, sıçramalar ve kayağa özgü hareketler içeren vibrasyon antrenman $(24-28 \mathrm{~Hz}, 2-4 \mathrm{~mm})$ programının postürel kontrole etkisi olmadığı ortaya konmuştur (Mahieu ve ark., 2006).

$\mathrm{Bu}$ sonuçların yanında vibrasyon antrenmanlarının dengeye pozitif etkileri olduğunu belirten araştırmalar da bulunmaktadır. Sağlıklı genç bireylerde vibrasyon platformu üzerinde dinamik hareketler içeren akut vibrasyon antrenmanını (4x60sn, $4 \mathrm{dk}, 15-30 \mathrm{~Hz}, 10 \mathrm{~mm}$ ) takip eden $2 \mathrm{dk}$ sonrası denge performansında artış olduğunu göstermiştir (Torvinen ve ark., 2002a). Yine benzer şekilde genç sağlıklı bireylerde 4 haftalık, haftada 3 gün uygulanan $10^{\circ}$ derece diz eklem açısındaki ayakta duruş pozisyonunu içeren vibrasyon antrenmanının $(25 \mathrm{~Hz}, 4 \mathrm{~mm}, 2$ set, set süresi $3-8 \mathrm{dk})$ dengeye pozitif etkisi olduğu (Ritzmann ve ark., 2014) belirtilmiştir.

Sağlıklı bireylerin yanında sporcularda yapılan vibrasyon antrenmanlarının pozitif etkileri olduğunu gösteren araştırma sonuçları da bulunmaktadır. Örneğin, 
Kaçoğlu, C. (2019). Akut Tüm Vücut Vibrasyon Antrenmanının Ünilateral Statik Dengeye Etkilerinin İncelenmesi. Gaziantep Üniversitesi Spor Bilimleri Dergisi, 4(1), 144-156.

ritmik jimnastikçilerde dinamik squat içeren akut vibrasyon antrenmanından $(30 \mathrm{~Hz}$, $2 \mathrm{~mm}$ ) 15dk sonra test edilen denge performansında anterior yönlü artı̧ gösterdiği belirtilmiştir (Despina ve ark., 2014). Elit erkek voleybolcularda ise 8 haftalık (haftada 3 gün, 30dk, $8-26 \mathrm{~Hz}$ ) vibrasyon antrenman programının dengeye pozitif etkisinin olduğunu gösteren sonuçlar bulunmaktadır (Kim ve ark., 2016). Bunun yanında elit ve amatör erkek futbolcularda akut vibrasyon antrenmanının (statik squat 3x60sn, $40 \mathrm{~Hz}, 4 \mathrm{~mm}$ ) dengeyi arttırdığını belirtmişler ve bunun olası esneklik artışından kaynaklı olabileceği şeklinde yorumlamışlardır (Cloak ve ark., 2016). Buna göre sağlıklı bireylerde ve sporcularda uygulanan vibrasyon antrenmanlarının parametrelerindeki farklıııların sonuçlar üzerinde etkili olduğu akla gelmektedir. Bunun yanında bireyin vibrasyon platformu üzerinde başa aktarılan sarsıntının diz eklemlerinin hafif fleksiyonda olduğu pozisyonda kısa süreli vibrasyonlar sırasında az olduğu ve vibrasyon egzersizlerinin güvenli olduğu belirtilmektedir. Fakat yine de çok yüksek frekanslarda uygulanan vibrasyonun araç tutmasına benzer bir etkiye neden olabileceği ve çok uzun vibrasyona maruz kalmanın da sağılı üzerine negatif etkileri olabileceği belirtilmiştir (Cardinale ve Wakeling, 2005). Buna göre frekans $(\mathrm{Hz})$, genlik (amplitüd) (mm), ivmelenme ( $\mathrm{ms}^{-2}$ veya $\mathrm{g}$ ) ve uygulama süresi (dk veya $\mathrm{sn}$ ) gibi antrenman parametrelerinin vibrasyonun dengeye etkilerinde oldukça büyük paya sahip olduğu söylenebilir.

Literatürde genç bireylerde farklı araştırma sonuçları olmasının yanında yaşlı bireylerde yapılan vibrasyon çalışmaları da bulunmaktadır. Yaşlı bireylerde 6 haftalık vibrasyon antrenmanlarının $(30-50 \mathrm{~Hz}, 2-5 \mathrm{~mm})$ dengeye pozitif etkisi olduğu (Bautmans ve ark., 2005), yine yaşlı bireylerde 2 ay, haftada 1 gün uygulanan vibrasyon antrenman programının $(12-20 \mathrm{~Hz}, 4 \mathrm{dk})$ ünilateral dengeye pozitif etkileri olduğunu (Kawanabe ve ark., 2007) gösteren araştırma sonuçları bulunmaktadır. Yaşlı kadınlarda 3 ay, haftada 3 günlük $(3 \mathrm{dk}, 20 \mathrm{~Hz})$ vibrasyon antrenman programının dengeye pozitif etkileri olmakla birlikte (Cheung ark., 2007),1 yıl süreyle haftada 3 gün uygulanan vibrasyon antrenmanının da $(35-40 \mathrm{~Hz}, 2.5-5 \mathrm{~mm})$ postürel kontrole pozitif etkisinin olduğunu gösteren araştırma sonuçları bulunmaktadır (Bogaerts ve ark., 2007). Bu sonuçlara göre yaşlı popülasyonda vibrasyonun etkilerinin daha belirgin olduğu görülmektedir. Buna göre denge yeteneğinin nispeten daha düşük olduğu bireylerde vibrasyonun tedavi amaçlı kullanımının pozitif etkilerinin daha belirgin olduğu söylenebilir. Bu araştırmanın sonuçlarının göz önünde 
Kaçoğlu, C. (2019). Akut Tüm Vücut Vibrasyon Antrenmanının Ünilateral Statik Dengeye Etkilerinin İncelenmesi. Gaziantep Üniversitesi Spor Bilimleri Dergisi, 4(1), 144-156.

bulundurularak antrenör ve sporcuların vibrasyon antrenmanlarını planlamada yardımcı olacağı düşünülmektedir.

Sonuç olarak, akut vibrasyon antrenmanının bu parametrelerle uygulanan (2x60sn, $30 \mathrm{~Hz}, 2 \mathrm{~mm})$ formunun sağlıklı bireylerde dengeye etkisi yoktur. İleride yapılacak çalışmalarda uzun süreli vibrasyon antrenman programının dengeye veya atletik performansa etkileri araştırılabileceği gibi farklı antrenman parametrelerinin karşılaştırmalı incelemesi yapılabilir.

\section{Kaynaklar}

Armstrong, W.J., Nestle, H.N., Grinnell, D.C., Cole, L.D., Van Gilder, E.L., Warren, G.S., \& Capizzi, E.A. (2008). The acute effect of whole-body vibration on the hoffmann reflex. The Journal of Strength \& Conditioning Research. 22(2), 471476.

Aydog, E., Depedibi, R., Bal, A., Eksioglu, E., Unlu, E., \& Cakci, A. (2005). Dynamic postural balance in ankylosing spondylitis patients. Rheumatology. 45(4), 445448.

Aykora, E., Tekin, A., Tekin, G., Aykora, D. (2017). 12 Haftalık Tüm Vücut Titreşim Antrenmanının Sedanter Kadın Öğrencilerin Bazı Fiziksel Uygunluk Özelliklerine Etkisi. Gaziantep Üniversitesi Spor Bilimleri Dergisi. 4(2), 65-79

Bautmans, I., Van Hees, E., Lemper, J.C., \& Mets, T. (2005). The feasibility of whole body vibration in institutionalised elderly persons and its influence on muscle performance, balance and mobility: A randomised controlled trial. BMC geriatrics. 5(1), 17.

Bogaerts, A., Verschueren, S., Delecluse, C., Claessens, A.L., \& Boonen, S. (2007). Effects of whole body vibration training on postural control in older individuals: a 1 year randomized controlled trial. Gait \& posture. 26(2), 309-316.

Bosco, C., Iacovelli, M., Tsarpela, O., Cardinale, M., Bonifazi, M., Tihanyi, J., Viru, M., De Lorenzo, A. and Viru, A. (2000). Hormonal responses to whole-body vibration in men. European Journal of Applied Physiology. 81, 449-454.

Cardinale, M., \& Bosco, C. (2003). The use of vibration as an exercise intervention. Exercise and sport sciences reviews, 31(1), 3-7.

Cardinale, M., \& Wakeling, J. (2005). Whole body vibration exercise: are vibrations good for you?. British journal of sports medicine. 39(9), 585-589. 
Kaçoğlu, C. (2019). Akut Tüm Vücut Vibrasyon Antrenmanının Ünilateral Statik Dengeye Etkilerinin İncelenmesi. Gaziantep Üniversitesi Spor Bilimleri Dergisi, 4(1), 144-156.

Cardinale, M, Rittweger, J. (2006). Vibration exercise makes your muscles and bones stronger: Fact or fiction? J Br Menopause Soc. 12:12-18

Cheung, W.H., Mok, H.W., Qin, L., Sze, P.C., Lee, K.M., \& Leung, K.S. (2007). Highfrequency whole-body vibration improves balancing ability in elderly women. Archives of physical medicine and rehabilitation. 88(7), 852-857.

Cloak, R., Nevill, A., \& Wyon, M. (2016). The acute effects of vibration training on balance and stability amongst soccer players. European journal of sport science. 16(1), 20-26.

Cochrane, D.J., \& Stannard, S.R. (2005). Acute whole body vibration training increases vertical jump and flexibility performance in elite female field hockey players. British journal of sports medicine. 39(11), 860-865.

Cochrane, D.J., Stannard, S.R., Firth, E.C., \& Rittweger, J. (2010). Acute whole-body vibration elicits post-activation potentiation. European journal of applied physiology, 108(2), 311. Physical Education and Sport. 16(1), 38.

Cochrane, D. (2013). The sports performance application of vibration exercise for warm-up, flexibility and sprint speed. European Journal of Sport Science. 13(3), 256-271.

Dallas, G., Kirialanis, P., \& Mellos, V. (2014). The acute effect of whole body vibration training on flexibility and explosive strength of young gymnasts. Biology of sport. 31(3), 233

Delecluse, C., Roelants, M., \& Verschueren, S. (2003). Strength increase after whole-body vibration compared with resistance training. Medicine \& Science in Sports \& Exercise. 35(6), 1033-1041.

Demirel, N., Sönmez, G.T., Eroğlu, H., \& Vatansever, Ş. (2017). The Effects of Gymnastics and Whole Body Vibration Exercises on Body Composition. Journal of Physical Education. 4(1), 25-33.

De Paula, L.V., Moreira, P.V., Huebner, R., Szmuchrowski, L.A. (2017). Indirect sinusoidal vibrations induces an acute increase in explosive strength. Journal of Electromyography and Kinesiology. 35, 76-85.

Despina, T., George, D., George, T., Sotiris, P., George, K., Maria, R., \& Stavros, K. (2014). Short-term effect of whole-body vibration training on balance, flexibility and lower limb explosive strength in elite rhythmic gymnasts. Human movement science. 33, 149-158. 
Kaçoğlu, C. (2019). Akut Tüm Vücut Vibrasyon Antrenmanının Ünilateral Statik Dengeye Etkilerinin İncelenmesi. Gaziantep Üniversitesi Spor Bilimleri Dergisi, 4(1), 144-156.

Dolny, D.G., \& Reyes, G.F.C. (2008). Whole body vibration exercise: training and benefits. Current sports medicine reports. 7(3), 152-157.

Fagnani, F., Giombini, A., Di Cesare, A., Pigozzi, F., \& Di Salvo, V. (2006). The effects of a whole-body vibration program on muscle performance and flexibility in female athletes. American journal of physical medicine \& rehabilitation. 85(12), 956-962.

Fratini, A., La Gatta, A., Cesarelli, M., \& Bifulco, P., (2009). Whole Body Vibration training: Analysis and characterization, In 9th International Conference on Information Technology and Applications in Biomedicine, (ITAB) 4-7 November, Larnaca, 1-4.

Fontana, T.L., Richardson, C.A., \& Stanton, W.R. (2005). The effect of weightbearing exercise with low frequency, whole body vibration on lumbosacral proprioception: A pilot study on normal subjects. Australian Journal of Physiotherapy. 51(4), 259-263.

Jordan, J.M., Norris, R.S., Smith, D.J., Herzog, W., (2005). Vibration Training: An Overview of the Area, Training Consecuences, and Future Considerations. Journal of Strenght and Conditioning Research. 19(2), 459-466.

Kaçoğlu, C., \& Gürol, B. (2016). Effect of body position during whole body vibration on acute jumping performance. Baltic Journal of Sport and Health Sciences. 3(102), 8-12.

Kaçoğlu, C., Yıldırım, U., (2017). İzometrik Önkondisyonlanma Kontraksiyonunun Sıçrama Performansına Akut Etkileri. Spor ve Performans Araştırmaları Dergisi. 8(3): 183-194.

Karatrantou, K., Gerodimos, V., Dipla, K., \& Zafeiridis, A. (2013). Whole-body vibration training improves flexibility, strength profile of knee flexors, and hamstrings-to-quadriceps strength ratio in females. Journal of science and medicine in sport. 16(5), 477-481.

Kawanabe, K., Kawashima, A., Sashimoto, I., Takeda, T., Sato, Y., \& Iwamoto, J. (2007). Effect of whole-body vibration exercise and muscle strengthening, balance, and walking exercises on walking ability in the elderly. The Keio journal of medicine. 56(1), 28-33.

Kırkaya, I., Şimşek, D., Ertan, H. (2015). The effects of vibration frequency variation on volleyball players' drop jump ability and postural control performance. Turkish Journal of Sport and Exercise. 17(2), 14-21. 
Kaçoğlu, C. (2019). Akut Tüm Vücut Vibrasyon Antrenmanının Ünilateral Statik Dengeye Etkilerinin İncelenmesi. Gaziantep Üniversitesi Spor Bilimleri Dergisi, 4(1), 144-156.

Kim, Y.Y., Min, K.O., Choi, J.H., \& Kim, S.H. (2016). The effects of sole vibration stimulation on Korean male professional volleyball players' jumping and balance ability. Journal of physical therapy science. 28(5), 1427-1431.

Mahieu, N.N., Witvrouw, E., Van de Voorde, D., Michilsens, D., Arbyn, V., \& Van den Broecke, W. (2006). Improving strength and postural control in young skiers: whole-body vibration versus equivalent resistance training. Journal of athletic training. 41(3), 286.

Melnyk, M., Schloz, C., Schmitt, S., \& Gollhofer, A. (2009). Neuromuscular ankle joint stabilisation after 4-Weeks WBV training. Int J Sports Med. 30(6), 461-466.

McBride, J.M., Nuzzo, J.L., Dayne, A.M., Israetel, M.A., Nieman, D.C., \& Triplett, N.T. (2010). Effect of an acute bout of whole body vibration exercise on muscle force output and motor neuron excitability. The Journal of Strength \& Conditioning Research. 24(1), 184-189.

Pérez-Turpin, J.A., Zmijewski, P., Jimenez-Olmedo, J.M., Jové-Tossi, M.A., Martínez-Carbonell, A., Suárez-Llorca, C., \& Andreu-Cabrera, E. (2014). Effects of whole body vibration on strength and jumping performance in volleyball and beach volleyball players. Biology of sport. 31(3), 239.

Poston, B., Holcomb, W.R., Guadagnoli, M.A., Linn, L.L., (2007). The Acute Effects of Mechanical Vibration on Power Output in The Bench Pres. Journal of Strenght and Conditioning Research. 21(1), 199-203.

Rønnestad, B.R., \& Ellefsen, S. (2011). The effects of adding different whole-body vibration frequencies to preconditioning exercise on subsequent sprint performance. The Journal of Strength \& Conditioning Research. 25(12), 33063310.

Rittweger, J. (2010). Vibration as an exercise modality: How it may work, and what its potential might be. European journal of applied physiology. 108(5), 877-904.

Rittweger, J., Beller, G., \& Felsenberg, D. (2000). Acute physiological effects of exhaustive whole-body vibration exercise in man. Clinical physiology. 20(2), 134-142.

Ritzmann, R., Kramer, A., Bernhardt, S., \& Gollhofer, A. (2014). Whole body vibration training-improving balance control and muscle endurance. PloS one. 9(2), e89905. 
Kaçoğlu, C. (2019). Akut Tüm Vücut Vibrasyon Antrenmanının Ünilateral Statik Dengeye Etkilerinin İncelenmesi. Gaziantep Üniversitesi Spor Bilimleri Dergisi, 4(1), 144-156.

Roelants, M., Delecluse, C., Goris, M., \& Verschueren, S. (2004). Effects of 24 weeks of whole body vibration training on body composition and muscle strength in untrained females. International journal of sports medicine. 25(01). 1-5.

Sá-Caputo, D.D.C., Ronikeili-Costa, P., Carvalho-Lima, R.P., Bernardo, L.C., BravoMonteiro, M.O., Costa, R., ... \& Arnobio, A. (2014). Whole body vibration exercises and the improvement of the flexibility in patient with metabolic syndrome. Rehabilitation research and practice. 2014.

Sands, W.A., McNeal, J.R., Stone, M.H., Russell, E.M., Jemni, M. (2006). Flexibility enhancement with vibration: Acute and long-term. Medicine \& Science in Sports \& Exercise. 38(4), 720-725.

Smith, D.R., Leggat, P. (2005). Whole-Body Vibration Health Effects, Measurement and Minimization. Proffesional Safety. 50(7), 35-40.

Torvinen, S., Kannus, P., SievaÈnen, H., Jaervinen, T.A., Pasanen, M., Kontulainen, S., ... \& Vuori, I. (2002a). Effect of a vibration exposure on muscular performance and body balance. Randomized cross-over study. Clinical physiology and functional imaging. 22(2), 145-152.

Torvinen, S., Sievänen, H., Järvinen, T.A.H., Pasanen, M., Kontulainen, S., \& Kannus, P. (2002b). Effect of 4-min vertical whole body vibration on muscle performance and body balance: A randomized cross-over study. International journal of sports medicine. 23(05), 374-379.

Torvinen, S., Kannus, P., Sievanen, H., Järvinen, T. A., Pasanen, M., Kontulainen, S., \& Vuori, I. (2002c). Effect of four-month vertical whole body vibration on performance and balance. Medicine \& Science in Sports \& Exercise. 34(9), 1523-1528.

Türkmen, F.C., Nezire, K. Vibrasyon: Fizyoterapide Kullanımı ve Etkileri. In: Fizyoterapi Seminerleri, Chapter 2, Ayşe K., Özlem Ü., Naciye V.Y., Muhammed K., Selen S.A. eds. Yayıncı: H.Ü.S.B.F. Fizyoterapi ve Rehabilitasyon Bölümü. 2016, p.11.

Ullucci, P.A., Tudini, F., \& Moran, M.F. (2019). Reliability of Smartphone Inclinometry to Measure Upper Cervical Range of Motion. Journal of sport rehabilitation. 28(1), 1-3. 